\title{
BONDABILITY OF BLACK LOCUST (Robinia pseudoacacia) AND BEECH WOOD (Fagus sylvatica) WITH POLYVINYL ACETATE AND POLYURETHANE ADHESIVES
}

\author{
Kamperidou Vasiliki, ${ }^{1, \triangleq}$ Barboutis Ioannis ${ }^{2}$
}

\begin{abstract}
In the previous years, black locust wood (Robinia pseudoacacia) has been participating in the European subsidizing programme of tree species cultivation, aiming in the establishing of new plantations in many European countries, therefore large quantities of this species is going to be harvested in the forthcoming years and the examination of its properties would be very crucial for future utilization. In the present research, the bondability of black locust wood is examined using two different adhesives, Polyvinyl acetate and Polyurethane and two different pressure levels. Beech wood is also included in the research for comparative reasons. According to the results, the shear bond strength of black locust wood was found to be satisfying, especially in the presence of Polyvinyl acetate adhesive and the less intensive pressure used during the specimens' construction, although it was found lower compared to beech wood, referring both to Polyvinyl acetate and Polyurethane adhesive.
\end{abstract}

Keywords: Adhesion, bonded wooden joints, pressure, shear bond strength, wood failure.

\section{INTRODUCTION}

The first reports of black locust wood use come from USA, where the natural development zone of this species is expanded, while the country with the largest area of black locust forest (about 300000 ha) worldwide is Hungary (Molnar 1995). In the previous years, black locust wood was included in the European subsidizing programme of tree species cultivation, aiming in the establishing of new plantations in many European countries. As a result, large quantities of black locust wood are going to be harvested in the forthcoming years and examination of the properties of the specific wood species and particularly the resistance of "wood to wood" adhesion and shear forces would be very useful and crucial for the future utilization of wood in structures and furniture frames construction.

The small diameters $(22-25 \mathrm{~cm})$ of black locust trunks, poorly developed logs, inclusions of branches and rotting heartwood constitute drawbacks to the wide industrial utilization of this wood species. The fact that black locust sawn timber is usually of small dimensions makes the axial and lateral welding and joining of this species be of great importance, since they are greatly applied in the construction of furniture, welded sleepers and welded beams and bearers. Additionally, black locust species is rarely used in the production of other wood based panels such as particleboard, fiberboard, etc., because of its high density, frequent poorly formed trunk and difficulties in barking procedure (Sakuno and Sano 1994). In addition, only the healthy and clear logs of a large enough diameter could be used for the production of veneers. Consequently, the utilization of black locust wood in the production of upholstered furniture frames or laminated panels and other structures for interior use is

\footnotetext{
${ }^{1}$ Doctor, Aristotle University of Thessaloniki, Faculty of Forestry and Natural Environment, Department of Harvesting and Technology of Forest Products, Thessaloniki, Greece, e-mail: vkamperi@for.auth.gr

${ }^{2}$ Professor, Aristotle University of Thessaloniki, Faculty of Forestry and Natural Environment, Department of Harvesting and Technology of Forest Products, Thessaloniki, Greece, e-mail: jbarb@for.auth.gr

"Corresponding author: vkamperi@for.auth.gr
}

Received: 29.11.2015 Accepted: 19.11.2016 
very critical and the expansion of knowledge on black locust wood behavior, mechanical and physical properties and adhesion parameters and abilities is undoubtedly imperative.

Apart from the established poly-condensation adhesives as UF-, MUF-, PF-, R(P)F resins, other adhesive systems such as polyurethanes (PUR) are gaining in popularity for surface gluing and special bonding applications in furniture and in load bearing timber structures. Polyurethanes are available in the form of 1 or 2 parts adhesive systems. One part types are classed as reactive adhesives and have prevailed in wood surface gluing, since they are simpler to handle and use the ability of wooden adherents to provide surface moisture that reacts with the free isocyanates in the urethane prepolymer to complete the cure (Richter and Steiger 2005). The isocyanate also reacts with the functional $\mathrm{OH}-$ groups of the adherent (Clauss et al. 2011). As previous researches showed, PUR adhesives exhibit excellent joint strength, when tested in standard climate conditions, but seem not to be so reliable in the case of low wood moisture content or under high temperatures, therefore PUR is characterized by a controversially discussed behavior and its use in load bearing timber structures could be unsafe (Richter and Steiger 2005, Beaud et al. 2006). Furthermore, Klaüsler et al. (2014) implemented tensile shear tests on European beech and Douglas fir bonded by means of a one-component PUR, revealing a substantial loss of tensile shear strength and wood failure percentage at the wet stage compared to the dry stage, as well as the necessity of testing different priming fluids.

Thermoplastic adhesives as PVAc are the most frequently used adhesives in non structural applications for interior use, applied at ambient temperature and they are cross-linked at the time of application. These adhesives are plasticized again when they are reheated and the process is reversible. PVAc is capable of producing strong and durable bonds on hardwoods and hardwood-derived products. Ordinary PVAc adhesives are marketed as milky, white fluids for use at room temperature, classified by durability class (D1, D2, D3 and D4) according to EN 204 standard, presenting an increase in bonding strength going from D1 to D3 class (Vassiliou et al. 2007).

Even though, PVAc and PUR are two commercially available adhesives being increasingly used in the construction of furniture frames and other interior applications, there is little information available concerning their durability behavior on black locust wood species. In order to examine the possibility of utilization of these forthcoming amounts of black locust wood (Robinia pseudoacacia) in furniture construction, this research was carried out examining the shear bond strength of this species, as well as beech wood (Fagus sylvatica) for comparative reasons, using Polyurethane and PVAc adhesive and two different levels of pressure during the construction of the joints. In each case, according to the procedure of the corresponding standard (ISO 6238:2001) the "wood to wood" bondability of the samples was revealed through shear strength tests, while after the destruction of each sample the percentage of the adhesive surface that was covered with ruptured wood (wood failure percentage) was estimated.

\section{EXPERIMENTAL METHODS}

The experiment was carried out using black locust (Robinia pseudoacacia L.) and beech (Fagus sylvatica L.) wood of Greek origin, naturally dried for one year. Beech wood was used for comparative reasons, since it is widely recommended by the current standards to use it as a 'comparative species' in bonding strength tests. The age of black locust wood was 25 years, while the one of beech wood was around 40 years. Suitable wood material, which was non-deficient, knotless, normally grown (without zone line reaction wood, decay or insect and fungal infections) was chosen to be used in the specific research work. The boards used in this experiment originated mainly from the heartwood part and were cut parallel to grain. The dimensions of the boards, intended to be assembled and bonded, were $30 \mathrm{~cm}$ in length $\times 5,5 \mathrm{~cm}$ in width $\times 2,5 \mathrm{~cm}$ in thickness and they were categorized in pairs to be assembled, 24 pairs totally. The boards were placed into a conditioned room at $20 \pm 2{ }^{\circ} \mathrm{C}$ temperature and $60 \pm$ $5 \%$ relative humidity and remained there to reach a nominal Equilibrium Moisture Content (EMC). Directly before the bonding process, the boards were knife-planed achieving the final thickness of $2 \mathrm{~cm}$, a necessary step that also excluded aging effects from the wood surfaces and ensured flat and smooth bonding surfaces. 
Two widely used adhesives of interior use were used in specimens' construction, that of PVAc of D3 class (Rakoll LP 8022) type and that of the Polyurethane (PUR of one component, Icema R 145 Professional). The adhesives were applied to the joints of the wooden elements, following the adhesive bonding parameters and the manufacturer's instructions. Prior to the spreading of PUR adhesive on wood, moisturizing of both wood surfaces, prepared for the adhesion, had preceded for each specimen, in order to contribute to the success of element bonding (Klaüsler et al. 2014), while in the case of PVAc moisturizing was not necessary (ISO 6238:2001). There is beneficial effect of water spray on the 1C PUR-gluing results, when the ambient conditions are very dry, leading to fast superficial drying of the wooden adherents (Klaüsler et al. 2014). PUR, generally reacts with the functional hydroxyl groups of wood creating strong chemical bonds, therefore, increasing the initial moisture content could have a positive effect on shear strength and glue penetration (Sedlia and Smidriakova 2010). The moisture content at the time of adhesive spreading was $10,44 \%$ for black locust and $8,7 \%$ for the beech wood. In each case, the adhesive was spread on both surfaces of the joint by a suitable comb hand-applicator (Figure 1a), while the glue quantity used in each surface of block was $4,5 \mathrm{~g}$.

Two different forms of pressure, 17,85 $\mathrm{kPa}$ (pressure A) and 27,26 kPa (pressure B), were applied to the specimens using a specified device, a press of air pistons that exerts the required pressure evenly over the whole bonded area within $\pm 5 \%$ of the desired value. The pressure implemented by the pendulums of the pressing device continued to be applied till the completion of the adhesives' curing process, that lasted 1 hour for PVAc and 1,5 hours for PUR adhesive (Figure 1b).
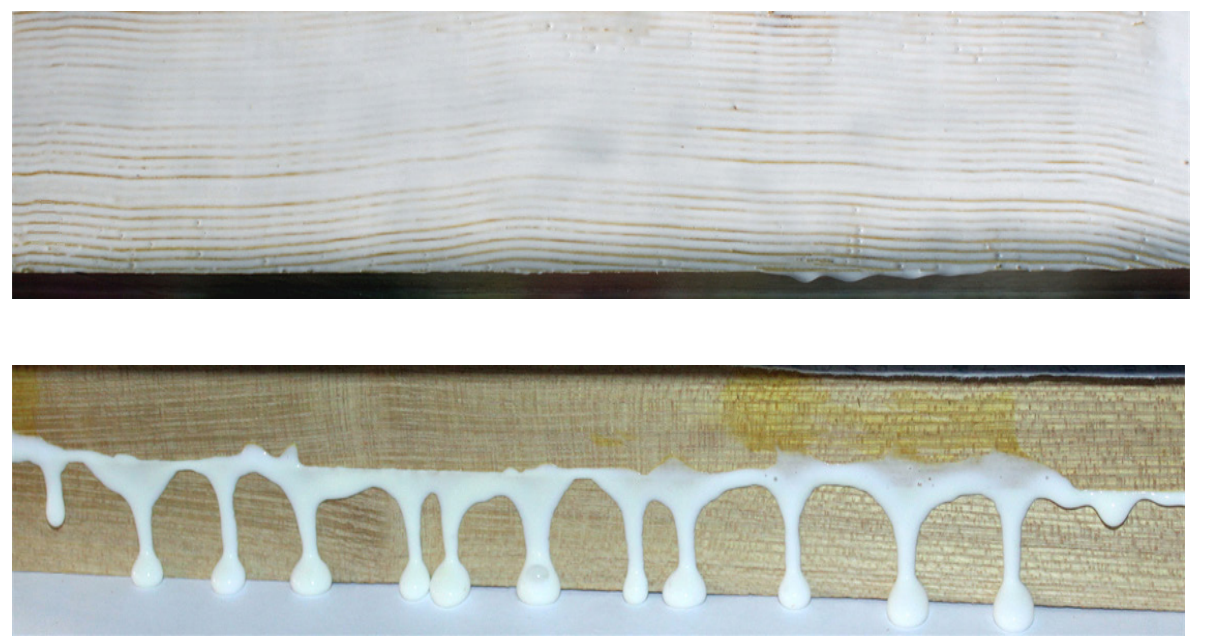

Figure 1. (a) Spreading of adhesive. (b) Application of pressure in blocks construction.

After one week's storage under standard climatic conditions, each bonded block was shaped in final dimensions of $29 \mathrm{~cm}$ length and $5 \mathrm{~cm}$ width (Figure 2, 3, 4), and they were cut into 5 specimens for the shear strength tests, according to ISO 6238:2001, to the final specimens' dimensions of 50mm x $40 \mathrm{~mm} \times 20 \mathrm{~mm}$ (Jauernig 1997). After their preparation, the test specimens remained for the period of one week, under controlled conditions of humidity $(65 \%)$ and temperature $\left(20^{\circ} \mathrm{C}\right)$ until the moment of testing, for the purpose of conditioning and completion of the adhesive polymerization. For each test, a number of 15 specimens were constructed, while for the whole research work 120 joint specimens were totally used. 


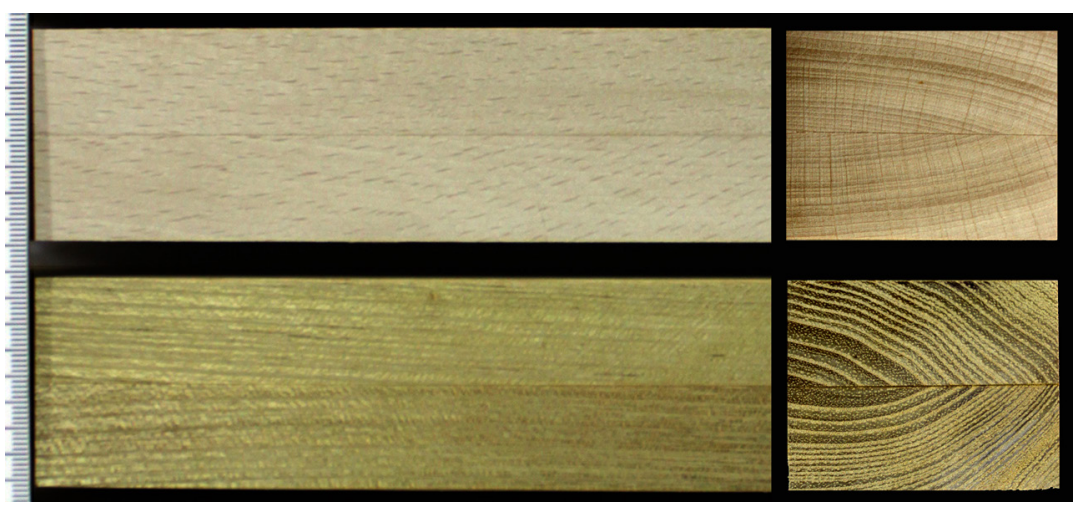

(a)

Figure 2. The PVAc bonded blocks of beech wood (a) and black locust wood block (b) (pressure of $17,85 \mathrm{kPa}$ ) presented alongside and their cross-section.

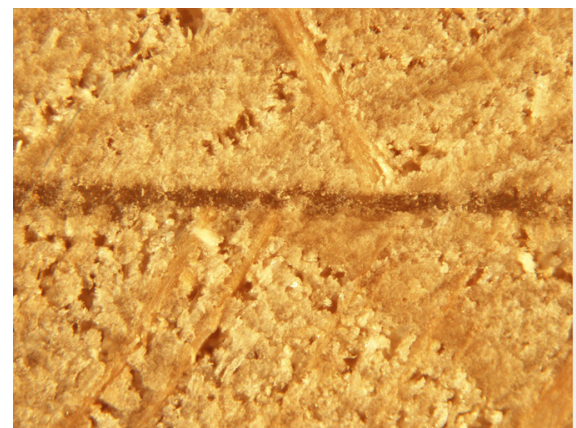

(a)

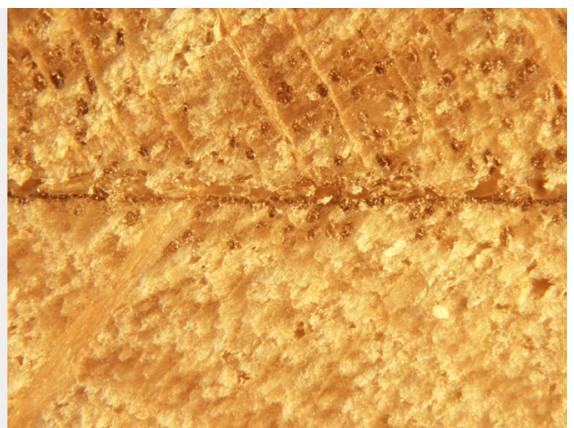

(b)

Figure 3. Bonding line in beech wood specimens (a) with PVAc (b) with PUR adhesive (48 X).

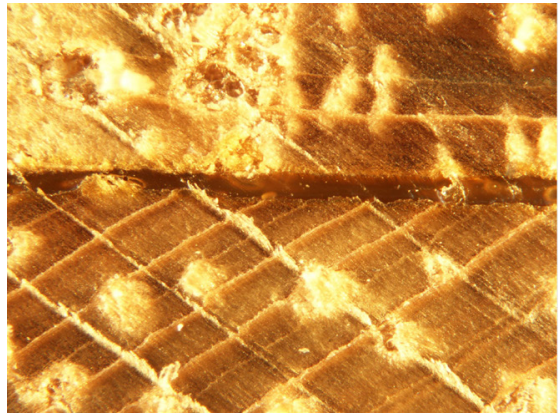

(a)

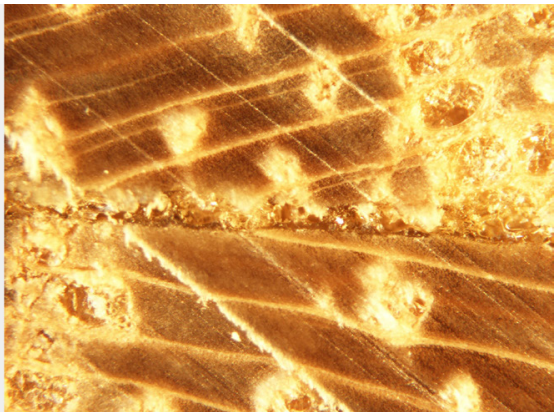

(b)

Figure 4. Bonding line in black locust wood specimens (a)with PVAc, (b) with PUR adhesive (48 X).

The Universal Testing Machine Shimadzu uh- 300kNA was used for the implementation of the shear tests at ambient conditions $\left(20^{\circ} \mathrm{C}\right)$, according to the procedure of ISO 6238:2001. The loading speed was $5 \mathrm{~mm} / \mathrm{min}$, while the loading was carried out until a complete separation or break in the surface of the test sample occurred, within $(60 \pm 20) \mathrm{s}$. Shear strength was estimated using the maximum load observed at the break point (Fmax in Newton) and the bonding surface of the sample $\left(\mathrm{mm}^{2}\right)$ ("a" is glued face width $(50 \mathrm{~mm})$ and " $\mathrm{b}$ " is glued face length $(40 \mathrm{~mm}))$, using the following equation: 


$$
S=\frac{F \max }{a \times b}
$$

After the completion of the shear strength test, the wood failure percentage was estimated visually, using a light source for the illumination of the bonding surface at a specific angle, as recommended by the standard (ISO 6238:2001). Both sides of the fracture were evaluated in conjunction and the wood failure percentage was evaluated at an approximation of $10 \%$.

After the end of strength tests, 20 specimens of black locust and 20 of beech wood were shaped and cut from the edges of the test specimens for the determination of density and moisture content of wood, according to standards (ISO 3131:1975) and (ISO 3130:1975), respectively. The average density of black locust wood was found to be $0,780 \mathrm{~g} / \mathrm{cm}^{3}$ and $0,722 \mathrm{~g} / \mathrm{cm}^{3}$ for beech wood and the average moisture content during the test process was $10,44 \%$ for black locust wood and $9,32 \%$ for that of beech wood specimens.

\section{RESULTS AND DISCUSSION}

According to the results (Table 1), the highest value of shear bond strength was recorded by beech wood specimens of PVAc constructed with the lower pressure of $17,85 \mathrm{kPa}(20,14 \mathrm{MPa})$. A little lower shear strength value was recorded by the same wood species of the same adhesive, but with higher pressure $(27,26 \mathrm{kPa})$ applied $(17,41 \mathrm{MPa})$. Quite good shear strength result was recorded also by black locust bonded with PVAc under lower pressure $(14,57 \mathrm{MPa})$, which was also statistically lower than the corresponding value of beech wood. The black locust wood specimens bonded with PVAc under higher pressure $(11,92 \mathrm{MPa})$ were proved to be of lower strength than the rest of the PVAc specimens, but of higher strength than all the other PUR specimens.

Table 1. Mean shear bond strength values (MPa) and percentage of wood failure (\%).

\begin{tabular}{|c|c|c|c|c|c|c|c|c|}
\hline \multirow{2}{*}{$\begin{array}{c}\text { Pressure } \\
\text { kPa }\end{array}$} & \multicolumn{4}{|c|}{ Black locust (MPa) } & \multicolumn{4}{c|}{ Beech (MPa) } \\
\cline { 2 - 9 } & PVAc & \% & PUR & \% & PVAc & \% & PUR & \% \\
\hline \multirow{2}{*}{$\mathbf{1 7 , 8 5}$} & 14,57 & 10 & 7,4 & 0,0 & 20,14 & 88,7 & 8,88 & 2,1 \\
& $(1,4)^{*}$ & $(10,9)^{*}$ & $(2,76)^{*}$ & $(0,0)^{*}$ & $(3,74)^{*}$ & $(14,6)^{*}$ & $(2,5)^{*}$ & $(3,2)^{*}$ \\
\hline \multirow{2}{*}{$\mathbf{2 7 , 2 6}$} & 11,92 & 8,4 & 6,39 & 0,0 & 17,41 & 79,7 & 6,01 & 0,5 \\
& $(1,05)^{*}$ & $(8,0)^{*}$ & $(1,59)^{*}$ & $(0,0)^{*}$ & $(1,07)^{*}$ & $(21,5)^{*}$ & $(1,51)^{*}$ & $(0,8)^{*}$ \\
\hline
\end{tabular}

*Standard deviation of 15 specimens.

Based on the results, PVAc specimens of black locust wood in every case presented higher shear bond strength compared to the corresponding PUR values. Specifically, referring to the lower pressure of $17,85 \mathrm{kPa}$, PVAc specimens of black locust recorded approximately $97 \%$ higher shear bond strength compared to corresponding PUR value, while referring to the higher pressure this percentage was $86,5 \%$. Regarding the beech wood specimens constructed under the lower pressure, PVAc recorded 127\% higher shear strength compared to PUR value, while the higher pressure of the specimens increased this difference percentage to around $190 \%$. The adhesive of PUR generally did not create strong chemical bonds neither with beech, nor with black locust wood, which could be attributed possibly to the fact that PUR adhesives do not penetrate the wood cell wall and generally, are regarded as adhesives with a significantly less polar character compared to other adhesives (Konnerth et al. 2009, Ammann et al. 2014). In every case, the specimens of PUR adhesive presented also higher variance values compared to PVAc specimens, which is also in agreement with previous researches (Richter and Steiger 2005). 


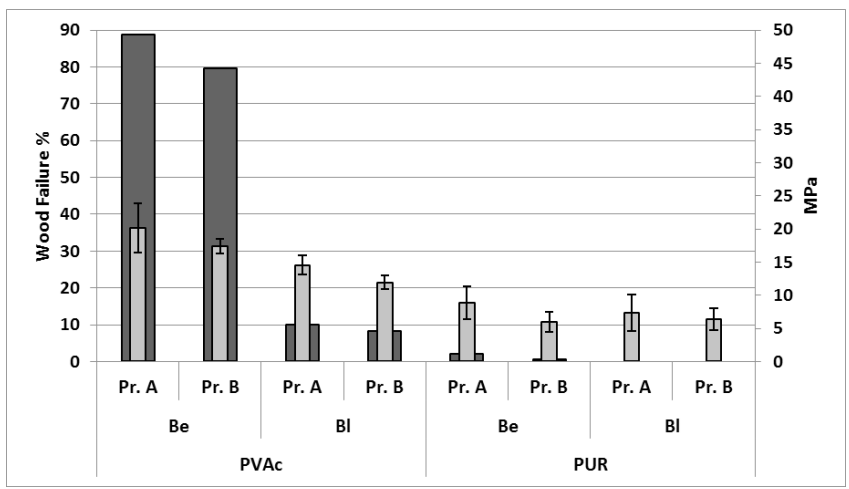

Figure 5. Configuration of shear bond strength values and wood failure percentages of black locust $(\mathrm{Bl})$ and beech wood (Be) (light grey bars correspond to shear strength, dark grey bars to wood failure percent) for lower (Pr.A) and higher pressure (Pr.B).

As it is easily detectable, the specimens constructed with the application of lower pressure (pressure A) marked higher shear strength values, in the case of both wood species and both adhesive types, compared to the more intensive pressure (pressure B), despite the fact that the adhesive manufacturers usually propose even higher pressures. This could be possibly attributed to the complicated synergy of the structure and density of wood, especially in the case of wood species of high density as black locust and beech wood are, and the nature of the adhesive. Specifically, PVAc black locust specimens of low pressure recorded approximately $22 \%$ higher shear strength compared to the corresponding specimens of higher pressure. Similarly, this difference percentage for PUR black locust specimens was 15,8\% while referring to PVAc and PUR beech wood this difference was $15,7 \%$ and $48 \%$, respectively, though that did not correspond to statistically significant differences.

Beech wood generally recorded higher shear bond strength values compared to the corresponding values of black locust wood, recording a statistically significant difference, especially in the case of PVAc adhesive, which could be attributed partly to the high extractives content of black locust wood, which possibly affects the polymerization process of the adhesives and this species bondability. Specifically, PVAc beech wood specimens of low pressure presented $38,2 \%$ higher shear bond strength compared to the corresponding mean value of black locust, while in the case of higher pressure, this percentage was $46 \%$. Respectively, PUR beech wood specimens of low pressure marked $20 \%$ higher strength value than the corresponding black locust value, while the only case that beech wood exhibited lower strength value than black locust was the case of PUR beech specimens of higher pressure that presented 6\% lower shear strength value than the corresponding black locust specimens. Probably, the adhesion quality of black locust wood could be improved through the development and use of technologies, such as steaming, priming, surface activation or plasma treatment, prior or parallel to the adhesion process, that could diminish the influence of the extractives content on the bondability of this species and eliminate this characteristic that tends to be a drawback (Varga and Van der Zee 2008).

Referring to the variables examined in this experiment, only beech wood specimens in the presence of PVAc adhesive were appeared to reach the strength levels of the wood itself. In previous research, Richter (2010) recorded a quite lower shear bond strength in black locust specimens of PVAc $(12,8$ $\mathrm{MPa}$ ) and a little higher shear strength values in specimens of PUR adhesive (9 MPa), but a marked difference between PVAc and PUR adhesive was also recorded. Higher strength values of black locust specimens with PUR adhesive (10,5 MPa), compared to the results of this research, were also presented by other researchers (Jauernig 1997). Voulgaridis et al. (2012), who examined the shear bond strength of black locust wood applying PVAc, PUR and epoxy adhesives under the constant pressure of 8 bars for 1,5 and 3 hours and a curing time of 24 hours or 7 days, found that PVAc presented slightly better 
bonds than PUR adhesive, while the best bonds were achieved by epoxy adhesive. They also noticed that increasing the pressing and curing time, the bond can be improved and that the surface roughness of wood is not a crucial factor for the shear bond strength.

The wood failure percent seemed to have a strong relation to the bonding strength levels (Figure 5) and was found to be very high $(79,7-88,7 \%)$ only in the case of PVAc beech wood specimens, while the PVAc black locust specimens demonstrated quite lower percentages $(8,4-10 \%)$, probably attributed to the extractives of this species. For both wood species, PUR specimens exhibited low percentages of wood failure $(0-2,1 \%)$ and consequently, relevantly poor bondability, a behavior that complies also with other researchers results (Voulgaridis et al. 2012).

\section{CONCLUSIONS}

Some of the basic conclusions that could be drawn from this research are the following:

The adhesive of Polyvinyl acetate (PVAc) exhibited better bonding performance and reliability than Polyurethane (PUR) adhesive for both species, black locust and beech wood and both levels of the pressure applied (pressure A and B). There are plenty of influencing factors that affect the adhesion of PUR (wettability of bonding surface, elasticity of adhesive in combination with hardwood species, etc.) and are still to be exhaustively investigated.

Beech wood specimens of both PVAc and PUR adhesives presented higher shear bond strength compared to the corresponding black locust values, probably because of the impact of the higher extractives content of black locust species that leaves the lumens of the surface line cells full and influences the $\mathrm{pH}$ of wood.

The specimens, in which lower pressure was applied (pressure A), marked higher shear strength values, in both wood species and for both adhesives, a fact probably attributed to the synergy between the anatomical structure and density of wood and the characteristics of the adhesive (viscosity, elasticity etc.).

Black locust wood in the presence of PVAc adhesive (constructed under the lower pressure - A), presented very satisfying shear bond strength values, that enables the further utilization of this species in a large variety of interior applications, competing other species traditionally used.

\section{REFERENCES}

Ammann, S.; Obersriebnig, M.; Konnerth, J.; Gindl, W.; Niemz, P. 2014. Comparative adhesion analysis at glue joints in European beech and Norway spruce wood by means of nanoindentation. International Journal of Adhesion \& Adhesives 50:45-49.

Beaud, F.; Niemz, P.; Pizzi, A. 2006. Structure - property relationships in one-component polyurethane adhesives for wood: Sensitivity to low moisture content. Journal of Applied Polymer Science 101(6): 4181-4192.

Clauss, S.; Joscak, M.; Niemz, P. 2011. Thermal stability of glued wood joints measured by shear tests. European Journal of Wood Products 69:101-111.

ISO 6238:2001. Adhesives-Wood-to-wood adhesive bonds - Determination of shear strength by compressive loading. 
ISO 3131:1975. Wood - Determination of density for physical and mechanical tests.

ISO 3130:1975. Wood - Determination of moisture content for physical and mechanical tests.

Jauernig, H. 1997. Research on the adhesion of black locust wood at higher moisture contents (Untersuchungen über die Verklebung von Robinie bei höheren Holzfeuchten). Diplom Holzwirt, Department of Biology, University of Hamburg, $60 \mathrm{pp}$.

Klaüsler, O.; Hass, P.; Amen, C.; Schlegel, S.; Niemz, P. 2014. Improvement of tensile shear strength and wood failure percentage of 1C PUR bonded wooden joints at wet stage by means of DMF priming. Eur J Wood Prod 72:343-354.

Konnerth, J.; Gierlinger, N.; Keckes, J.; Gindl, W. 2009. Actual versus apparent within cell wall variability of nanoindentation results from wood cell walls related to cellulose microfibril angle. J Mater Sci 44(16):4399-4406.

Molnar, S. 1995. Wood properties and utilization of Black Locust in Hungary. Drevarsky Vyskum $1: 27-33$.

Richter, H.G. 2010. Glued products manufacture and assessment (window scantlings, gluelam, glueboards). In: Technology for High Quality Products from Black Locust. International Conference, Bugac, Hungary, Oct. 8-11, 2010.

Richter, K.; Steiger, R. 2005. Thermal Stability of Wood - Wood and Wood - FRP Bonding with Polyurethane and Epoxy adhesives. Advanced Engineering Materials 7(5):419-426.

Sakuno, T.; Sano, I. 1994. Properties of particleboard and lumber-core board manufactured from sugi thinnings and lesser-used hardwood. Procceedings of the International Symposium on the Utilization of Fast-Growing Trees; 1994; Nanjing, P.R. China.

Sedlia, J.; Smidriakova, M. 2010. Shear strength of the joint wood - carbon lamella after moisture and heat conditioning. Annals of Warsaw University of Life Sciences - SGGW, For and Wood Technol. $72,2010$.

Varga, D.; Van Der Zee, M.E. 2008. Influence of steaming on selected wood properties of four hardwood species. European Journal of Wood and Wood Products 66(1):11-18.

Vassiliou, V.; Barboutis, I.; Karastergiou, S. 2007. Effect of PVAc Bonding on Finger-Joint Strength of Steamed and Unsteamed Beech Wood (Fagus sylvatica). Journal of Applied Polymer Science 103:1664-1669.

Voulgaridis, E.; Passialis, C.; Negri, M.; Adamopoulos, S. 2012. Shear bond strength of black locust wood glued with three adhesive systems. Wood Research 57(3):489-496. 